\title{
VARIATIVITY OF CLINICAL-PSYCHOPATHOLOGICAL CONTENT OF DISORDERS RELATED TO ALCOHOL CONSUMPTION IN PERSONS WITH DIFFERENT PSYCHOLOGIC TRAUMATIC EXPERIENCES AND LEVELS OF PSYCHOSOCIAL STRESS
}

\author{
Gaponov K.D.
}

\author{
Kharkiv Medical Academy of Postgraduate Education, Ukraine
}

\begin{abstract}
The article presents the results of a comprehensive survey of 312 men suffering from alcohol dependence: 107 combatants, 89 forcibly displaced persons and 116 civilians in the city of Kharkiv and Kharkiv region. The study has shown that the clinical diversity and severity of disorders associated with alcohol consumption (the style of alcohol consumption, the ability to control the attraction to consume, tolerance, the structure of the withdrawal state, etc.), and their psychopathological arrangement (depression, anxiety, interpersonal sensitivity, hostility, phobic anxiety, somatization, paranoia) are associated with the severity of psychosocial stress that the patients experience. The factor of the presence of psychotraumatic experience, not associated with a distinct response to a stressful event, does not significantly affect the variability of psychopathological symptoms of individuals with alcohol dependence. The revealed patterns should be taken into account when developing treatment and rehabilitation and preventive measures for persons suffering from alcohol dependence.

Key words: psychosocial stress, psychotraumatic experience, psychopathological manifestations, disorders related to the alcohol consumption.
\end{abstract}

\section{Introduction}

According to the results of a collaborative study of the global incidence of alcohol-related diseases in 195 countries of the world for the years from 1990 to 2016, published in the journal Lancet (2018), Ukraine ranks $2^{\text {nd }}$ in the world in terms of the number of years lost due to disability or premature death due to the alcohol consumption (DALY). Also, Ukraine ranks 2nd in the world in the number of years that Ukrainians live with alcoholism (YLD); according to the rate of death due to alcohol, Ukraine ranks 9th in the world, and the number of deaths associated with alcohol consumption is $1.3 \%$ of their total number [1].

Corresponding Author:

Kostiantyn Gaponov, MD, PhD, Chief Doctor of the Regional Clinical Hospital

"Regional Narcological Dispensary", of the of the Narcology Department at the Kharkiv Medical Academy of Postgraduate Education of the Ministry of Health of Ukraine, Ukraine. E-mail: kostiantyn1807@gmail.com
The above suggests low effectiveness of the existing system for providing medication.

The current state of the prevalence of alcohol dependence and the provision of medication to the population in the country is a reflection of socio-political processes taking place in Ukraine. First of all, it relates to the factors associated with the effect of suppressive stressors, such as political and economic instability and hostilities in the East of Ukraine [2-4].

The relationship between the presence of stress and the alcohol consumption is confirmed by a large number of studies with a significant evidence base and is recognized by all scientific schools and directions: the results of epidemiological, genetic, biochemical, neurophysiological, clinical researches convincingly testify to its presence $[5,6]$.

Meanwhile, in spite of the obvious need, the accumulation of this knowledge has not yet led to an understanding of how to use new knowledge to affect the reduction of harm from alcohol and the effectiveness of alcohol dependence treatment 
in people experiencing significant stress. Taking into account the systemic interaction of the two mentioned phenomena, approaches to treatment of alcohol dependence with comorbid post-stress conditions should be based on biopsychosocial principles, and existing therapeutic and rehabilitation strategies should be substantially modified taking into account the vector of stress on the formation and the course of alcohol dependence.

\section{Purposes, subjects and methods:}

2.1 Purpose - to analyze the peculiarities of the correlation between the variability of manifestations and the psychopathological arrangement of alcohol dependence, with the presence of psychotraumatic experience and the severity of psychosocial stress, to understand the ways of modification of existing therapeutic and rehabilitation strategies, taking into account the aggravating effect of stress on the formation and the course of alcohol dependence.

The hypothesis of the work was the statement that the factor of the presence of psychotraumatic experience itself not associated with a distinct response to a stressful event does not significantly affect the indices of the severity of alcohol-related disorders, which significantly influences the choice of therapeutic strategies for individual contingents of patients with alcohol dependence.

\subsection{Subjects \& Methods}

The study was carried out on the basis of the Municipal Non-Commercial Enterprise of Kharkiv Regional Council "Regional Narcological Dispensary" during 2014-2018, where upon condition of informed consent, being committed to the principle of bio-ethics and deontology, 312 men with alcohol dependence were examined: 107 combatants who had the experience of engaging in military actions on the East of Ukraine as participants in the AntiTerrorist Operation and Operation of the Joint Forces; 89 forcibly displaced persons from temporarily occupied districts of Donetsk and Lugansk region; and 116 residents of the city of Kharkiv and Kharkiv region who were not combatants or forcibly displaced persons.

The study included the use of clinical, clinicalpsychopathological and psycho-diagnostic methods. Alcohol dependence was diagnosed by clinico-psychopathological method that was supplemented, in addition to a clinical structured interview according to the diagnostic criteria of ICD-10, by psychodiagnostic studies using the AUDIT test (for identifying disorders associated with alcohol abuse and determining the degree of danger of its use) [7] and scales SADQ-C [8]. Measurement of the severity of psychosocial stress was carried out on the scale by L. Rider [9] and the scale of psychological stress by LemyrTessier-Fillion in edition of N. E. Vodopyanova (PSM-25) [10]. In addition to the severity of psychosocial stress, the severity and structure of post-traumatic stress was also assessed by means of the scale of the impact of the traumatic event by M. Horowitz in edition of N.V. Tarabrina [11]. The evaluation of the specificity of psychopathological symptoms was performed using the Symptom Check List-90-Revised-SCL90-R expressiveness questionnaire in edition of N.V. Tarabrina [11]. The statistical-mathematical analysis included the formation of descriptive statistics and the analysis of discrepancies using non-parametric methods: the Mann-Whitney test and Fischer's exact criterion.

Conflict of interests. There is no conflict of interests.

\section{Results and discussion}

According to the criterion of the severity of the psychosocial stress (according to L. Rider's scale), the patients were divided into the following three groups: with a low level -35 persons (the indicator on a scale is up to 0.99 points), with a moderate level -84 persons (the indicator is from 1.00 to 1.99 points), and with a high level 193 persons (the indicator is more than 2.00 points).

Relatively low level of psychosocial stress was determined in $2(1.9 \%)$ combatants (group C1), $9(10.1 \%)$ displaced persons (group DP1) and $24(20.7 \%)$ locals (group L1) (average indicator in the group is $0.62 \pm 0.21$ points). Moderate level of stress was detected in $29(27.1 \%)$ combatants (group C2), 22 (24.7\%) displaced persons (group DP2) and 33 (28.4\%) locals (group L2) (average indicator is $1.39 \pm 0.30$ points). Severe stress level was detected in $76(71.0 \%)$ combatants (group C3), 58 (65.2\%) displaced persons (group DP2) and $59(50.9 \%)$ urban residents (group L3) (average indicator is $2.47 \pm 0.38$ points). Differences in the comparison of the average severity of psychosocial stress in these groups were statistically significant $(p<0.01)$.

The average indices of the severity of psychosocial stress among people of different social groups were the following: among the combatants $-2.24 \pm 0.63$ points; displaced people $-2.03 \pm 0.72$ points; local residents $-1.68 \pm 0.78$ points (differences were statistically significant when comparing groups of combatants and locals, displaced persons and locals, $\mathrm{p}<0.01$ ). 
A similar tendency was found regarding the vulnerability to psychological stress (method PSM-25): the average severity of the combatants was $151.62 \pm 25.82$ points, of the displaced persons $-143.56 \pm 31.20$ points, of the locals $-131.09 \pm$ 36.04 points (differences in the comparison of combatants and displaced persons $\mathrm{p}>0.05$, combatants and locals $\mathrm{p}<0.01$, displaced persons and locals $\mathrm{p}<0.01$ ). The average indicator in the group of individuals with a low level of response to psychosocial stress was $72.46 \pm 9.37$ points, with a moderate level of response was $123.30 \pm$ 19.97 points, and with a severe level was 162.25 \pm 9.43 points (differences statistically significant in comparison all groups among themselves, $\mathrm{p}<0.01$ ). The study of the impact assessment of the traumatic event on the mental state of the respondents has proven the following. On the one hand, it is absolutely anticipated that the average severity of the impact of the psychotraumatic experience was higher among the combatants (52.83 \pm 22.12 points) than that of the displaced persons (47.67 \pm 22.02 points), and in the latter higher than in the local residents $(40.06 \pm$ 17.75 points) (differences are significant when comparing the numbers of combatants and / or displaced persons with locals - combatants vs. locals $\mathrm{p}<0.01$; displaced persons vs. locals $\mathrm{p}<0.05$; differences between combatants and displaced persons are not reliable $\mathrm{p}>0.05$ ). Meanwhile, the average severity of post-traumatic responses in individuals with a low level of psychosocial stress was $23.23 \pm 0.65$ points (upper limit of the low severity range), moderate $-28.61 \pm 3.86$ (lower limit of the range of moderate severity), severe $58.69 \pm 18.28$ points (range of high severity), while the differences were statistically significant in the comparison of all groups among themselves $(p<0.01)$. Thus, we can see that among the representatives of different contingents, including the presence of psychotraumatic experience "by default" (combatants and / or displaced persons), despite the traumatic events experienced, there are a significant number of people with low or insignificant severity of pathological posttraumatic stress. The intensity of the pathological effect of the traumatic event is due to the expressiveness of the stress response to it, which is associated with the severity of the tested psychosocial stress.

The severity of clinical manifestations of alcohol dependence also turned out to be heterogeneous among the surveyed people, but was associated with the level of psychosocial stress: in people with mild stress, the average rate on AUDIT scale was $15.17 \pm 2.32$ points, with a moderate response to stress $-21.53 \pm 1,99$ points, severe $-31.51 \pm 6.35$ points (differences are statistically significant when comparing all groups among themselves $p<0.01$ ). The average severity of alcohol dependence among combatants was $30.43 \pm 7.31$ points, displaced persons $-28.60 \pm$ 7.78 points, and locals $-25.43 \pm 8.19$ points (differences are statistically significant when comparing combatants and locals $\mathrm{p}<0.01$, displaced persons and locals $\mathrm{p}<0.01$ ).

Differences in the severity and clinical variability of the abolition state (SADQ-C scale) for the most part did not have statistical significance between patients of different social groups (combatants $-43.48 \pm 9.17$ points, displaced persons $-41.04 \pm 13.18$ points, $\mathrm{p}>0.05$; locals $35.49 \pm 16.02$ points, $p<0.01$ ), however, there were significant differences in the severity of psychosocial stress (table).

According to Table 1 data, the manifestations of the severity of alcohol dependence, first of all, symptoms of the first day of withdrawal, significantly differed depending on the level of psychosocial stress: in patients with severe stress, all the symptoms were more severe, in particular, hyperhidrosis, tremor and desire to drink of varying degrees of severity during the first and second-third days of withdrawal, as compared to the symptoms, inherent in persons with lower severity of psychosocial stress. For patients with the moderate level, the most severe symptoms were symptoms of hyperhidrosis, tremor, as well as the desire to drink in the first day of withdrawal. In individuals with mild psychosocial stress, there were single affective symptoms and manifestations of tolerance.

Further analysis of the clinical content of alcohol-related disorders had a significant difference, depending on the level of psychosocial stress experienced by the patients (fig. 1).

In patients with a low level of psychosocial stress, the clinical-psychopathological picture of alcohol dependence predominated $(p<0.01)$ : oneday excesses $(48.6 \%)$ or pseudo dipsomania (42.9\%); situational primary attraction to alcohol, arising periodically, was more often provoked by external factors $(100 \%)$; a strong desire or an insuperable desire to consume alcohol that was manifested by a secondary attraction that arose after any dose of alcohol, with a partial loss of quantitative control $(60.0 \%)$ or a symptom of a critical dose (40.0\%); the absence of pathological time course of clinical manifestations of intoxication (97.1\%). 
Clinical variability of the structure of withdrawal state in people with different levels of psychosocial stress (on the scale of SADQ-C)

\begin{tabular}{|c|c|c|c|c|c|c|c|}
\hline \multirow{2}{*}{ No. } & \multirow{2}{*}{$\begin{array}{c}\text { Manifestations } \\
\text { of severity } \\
\text { of alcohol dependence } \\
\text { on the scale of SADQ-C }\end{array}$} & \multicolumn{3}{|c|}{ Level of psychosocial stress } & \multicolumn{3}{|c|}{$\begin{array}{c}\text { Level of statistical significance } \\
\text { of differences }\end{array}$} \\
\hline & & low & moderate & severe & p 1-2 & p 1-3 & p 2-3 \\
\hline \multicolumn{8}{|c|}{ Manifestations of the first day of withdrawal syndrome, $\mathrm{M} \pm \mathrm{m}$} \\
\hline 1 & Some hyperhidrosis & $0.09 \pm 0.28$ & $2.14 \pm 0.73$ & $3.37 \pm 0.58$ & $<0.01$ & $<0.01$ & $<0.01$ \\
\hline 2 & Hands tremor & $0.14 \pm 0.36$ & $2.38 \pm 0.77$ & $2.97 \pm 0.82$ & $<0.01$ & $<0.01$ & $<0.01$ \\
\hline 3 & Body tremor & $0.14 \pm 0.36$ & $1.40 \pm 0.49$ & $2.33 \pm 0.95$ & $<0.01$ & $<0.01$ & $<0.01$ \\
\hline 4 & Intense hyperhidrosis & $0.17 \pm 0.38$ & $1.63 \pm 0.62$ & $2.26 \pm 0.95$ & $<0.01$ & $<0.01$ & $<0.01$ \\
\hline 5 & Fear & $0.17 \pm 0.38$ & $1.50 \pm 0.59$ & $2.23 \pm 0.84$ & $<0.01$ & $<0.01$ & $<0.01$ \\
\hline 6 & Fear of meeting people & $0.17 \pm 0.45$ & $1.56 \pm 0.52$ & $2.04 \pm 0.78$ & $<0.01$ & $<0.01$ & $<0.01$ \\
\hline 7 & The face of despair & $0.40 \pm 0.55$ & $1.98 \pm 0.79$ & $2.07 \pm 0.94$ & $<0.01$ & $<0.01$ & $>0.05$ \\
\hline 8 & Fright & $0.43 \pm 0.56$ & $1.62 \pm 0.74$ & $1.80 \pm 0.85$ & $<0.01$ & $<0.01$ & $>0.05$ \\
\hline 9 & Desire to drink & $0.51 \pm 0.82$ & $1.56 \pm 0.72$ & $1.48 \pm 0.72$ & $<0.01$ & $<0.01$ & $>0.05$ \\
\hline 10 & Strong desire to drink & $0.80 \pm 0.90$ & $1.58 \pm 0.84$ & $1.54 \pm 0.79$ & $<0.01$ & $<0.01$ & $>0.05$ \\
\hline 11 & $\begin{array}{l}\text { Need to drink } \\
\text { for tremor removal }\end{array}$ & $0.54 \pm 0.78$ & $1.43 \pm 0.66$ & $1.64 \pm 0.86$ & $<0.01$ & $<0.01$ & $>0.05$ \\
\hline 12 & $\begin{array}{l}\text { Very strong desire } \\
\text { to drink }\end{array}$ & $0.31 \pm 0.68$ & $1.69 \pm 0.90$ & $1.91 \pm 1.13$ & $<0.01$ & $<0.01$ & $>0.05$ \\
\hline \multicolumn{8}{|c|}{ Daily tolerance, $M \pm m$} \\
\hline 13 & $\begin{array}{l}\text { Tolerance of more than } \\
250 \mathrm{ml} \text { of vodka }\end{array}$ & $0.49 \pm 0.66$ & $1.58 \pm 0.93$ & $1.98 \pm 1.09$ & $<0.01$ & $<0.01$ & $<0.01$ \\
\hline 14 & $\begin{array}{l}\text { Tolerance } \\
\text { of more than } \\
500 \text { ml of vodka }\end{array}$ & $0.34 \pm 0.59$ & $1.44 \pm 0.97$ & $2.28 \pm 1.17$ & $<0.01$ & $<0.01$ & $<0.01$ \\
\hline 15 & $\begin{array}{l}\text { Tolerance of more than } \\
1 \text { I of vodka }\end{array}$ & $0.40 \pm 0.50$ & $1.70 \pm 0.92$ & $2.04 \pm 1.09$ & $<0.01$ & $<0.01$ & $<0.05$ \\
\hline 16 & $\begin{array}{l}\text { Tolerance of more than } \\
2 \text { I of vodka }\end{array}$ & $0.06 \pm 0.24$ & $1.86 \pm 1.05$ & $1.90 \pm 1.08$ & $<0.01$ & $<0.01$ & $>0.05$ \\
\hline \multicolumn{8}{|c|}{ Manifestations of the second-third day of withdrawal syndrome, $\mathrm{M} \pm \mathrm{m}$} \\
\hline 17 & Salivation & $0.80 \pm 0.83$ & $1.89 \pm 1.15$ & $2.51 \pm 1.09$ & $<0.01$ & $<0.01$ & $<0.01$ \\
\hline 18 & Hands tremor & $0.83 \pm 0.98$ & $2.23 \pm 1.32$ & $3.40 \pm 1.04$ & $<0.01$ & $<0.01$ & $<0.01$ \\
\hline 19 & Body tremor & $0.97 \pm 0.66$ & $2.23 \pm 0.72$ & $3.11 \pm 0.94$ & $<0.01$ & $<0.01$ & $<0.01$ \\
\hline 20 & $\begin{array}{l}\text { Very strong desire } \\
\text { to drink }\end{array}$ & $1.37 \pm 1.52$ & $3.49 \pm 0.94$ & $3.77 \pm 0.56$ & $<0.01$ & $<0.01$ & $<0.01$ \\
\hline
\end{tabular}

A characteristic feature of the clinical image of alcohol dependence, inherent in this category of patients, was the absence of a clinically defined syndrome of withdrawal and awareness of the harmful effects of alcohol dependence.

In patients with the moderate stress level, the primary attraction to alcohol developed independently of the provocative effect of external factors $(44.0 \%)$, or was of the nature of the internal unconscious need (26.2\%); consumption was carried out in the form of pseudo dipsomania $(35.7 \%)$ or permanent consumption secondary to high tolerance $(36.9 \%)$; characterized by an impairment of the capacity of quantitative control with partial (38.1\%) or total loss $(59.5 \%)$, as well as restriction of the repertoire of alcohol consumption, loss of the importance of such factors as place, time and environment during its consumption; manifestations of somatic harm (complications in the cardiovascular system $-52.4 \%$, intestinal system $-34.5 \%$ ); non-severe withdrawal state; the primary amount partially recognized and formally did not deny the presence of harmful effects of alcohol abuse $(p<0.01)$.

Persons with the high level of stress were found to have the following $(\mathrm{p}<0.01)$ : constant alcohol consumption secondary to high $(42.5 \%)$ or low $(36.8 \%)$ tolerance; spontaneous, without struggle of motives $(47.7 \%)$, or compulsive primary pathological attraction to alcohol (36.8\%); loss of a quantitative $(53.9 \%)$ or situational $(43.0 \%)$ control in a state of intoxication with a change in its form: a change in the form of intoxication with a depressive and anxiety component was characteristic for $15.5 \%$ of patients, previously unusual aggression in the combination with motor activity in a state of intoxication was found in $13.0 \%$ of patients (psychopathic behavior was manifested by explosiveness, predisposition to non-motivated aggression, and asocial actions), intoxication with features of polymorphic symptoms of the 
Constant alcohol consumption, despite obvious evidence of its harmful effects

Progressive narrowing of the spectrum of alternative pleasures, forms

Narrowing the range of alcoholic beverages that are being used

\author{
Abstinence state \\ Alcohol consumption to suppress or prevent \\ abstinence symptoms \\ Psychological or somatic harm \\ Tolerance (physiological, behavioral or \\ psychological) \\ Disrupted ability to control alcohol \\ consumption ("loss of control") \\ Strong desire or inexorable desire to consume \\ alcohol ("thirst")
}
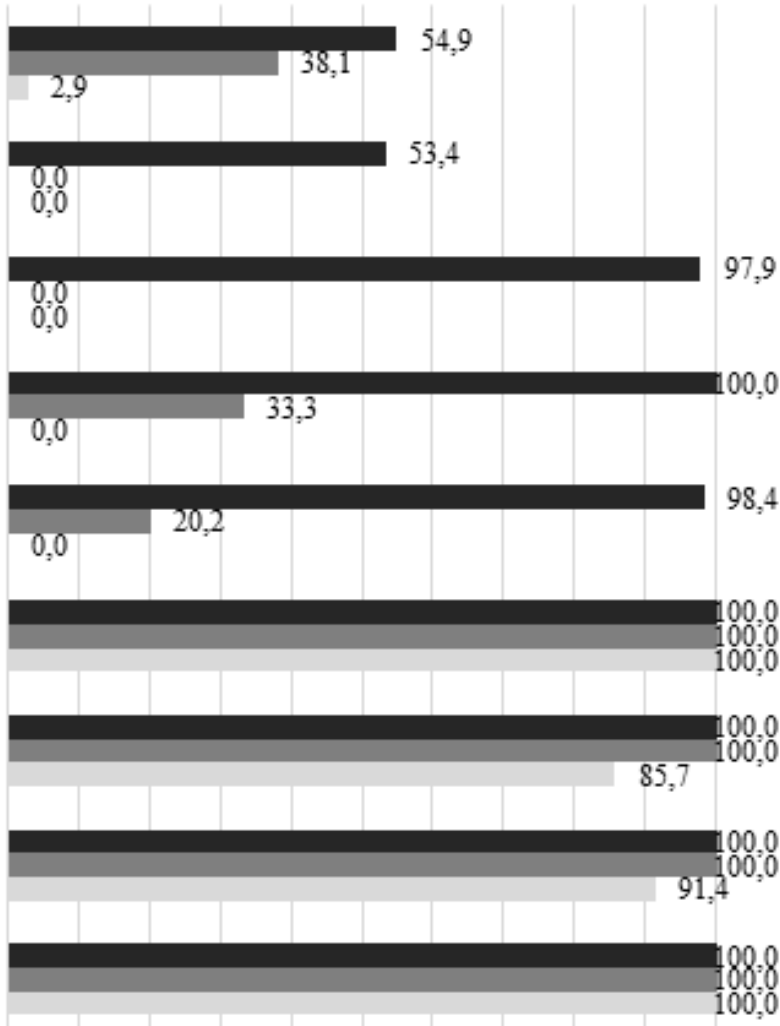

$0,010,020,030,040,050,060,070,080,090,0100,0$

- Severe moderate mild

Fig. 1. Clinical specificity of disorders associated with alcohol consumption in people with different levels of psychosocial stress

dysphoric-explosive component was observed in $8.3 \%$ of the patients.

Furthermore, this category of examined patients was found to have: severe withdrawal syndrome with a compulsive-vital pathological attraction in its structure; a progressive loss of alternative interests in favor of the alcohol consumption and a longer time to buy and consume it; alcohol anosognosia and continuation of alcohol consumption, despite its obvious harmful somatic, psychological (affective and cognitive) consequences: the combination of affective flattening and indifference to the environment and severe somatic and vegetative manifestations.

The specificity of comorbid psychopathological arrangement was also determined by the level of stress experienced by the patients: an increase in the severity of psychopathological symptoms as increased severity of psychosocial stress was recorded.

Thus, among the combatants (groups C1, C2, $\mathrm{C} 3$ in fig. 2), the differences noted were most severe for depression, obsessive-compulsive symptoms, and somewhat less for somatization, interpersonal sensitivity and psychosis. The General Symptomatic Index (GSI) was increasing with an increase in the severity of psychosocial stress: in the $\mathrm{C} 1$ group it was $0.45 \pm 0.07$ points, in the $\mathrm{C} 2$ group it was $0.57 \pm 0.21$ points, in the $\mathrm{C} 3$ group it was $0.71 \pm 0.26$ points. The Positive Symptomatic Index (PSI) was the highest in the C3 group (30.00 \pm 8.52 points), slightly less in the $\mathrm{C} 2$ group ( $27.50 \pm 2.12$ points), and the lowest in the $\mathrm{C} 1$ group ( $26.48 \pm 7.19$ points). Significant $(p<0.05)$ discrepancies between the groups were found for the Positive Distress Symptomatic Index (PDSI), with a tendency to increase the severity of distress as the severity of psychosocial stress increased: in the $\mathrm{C} 1$ group, the rate was $1.40 \pm$ 0.10 points, in the $\mathrm{C} 2$ group $-1.90 \pm 0.27$ points, in the $\mathrm{C} 3$ group $-2.11 \pm 0.28$ points.

The forcibly displayed persons (groups DP1, DP2, DP3) maintained the same general tendencies to increase the indices of the severity of psychopathological symptoms combined with the increase in the severity of psychosocial stress (Fig. 3): displaced persons with alcohol dependence, with a low degree of psychosocial stress, were 


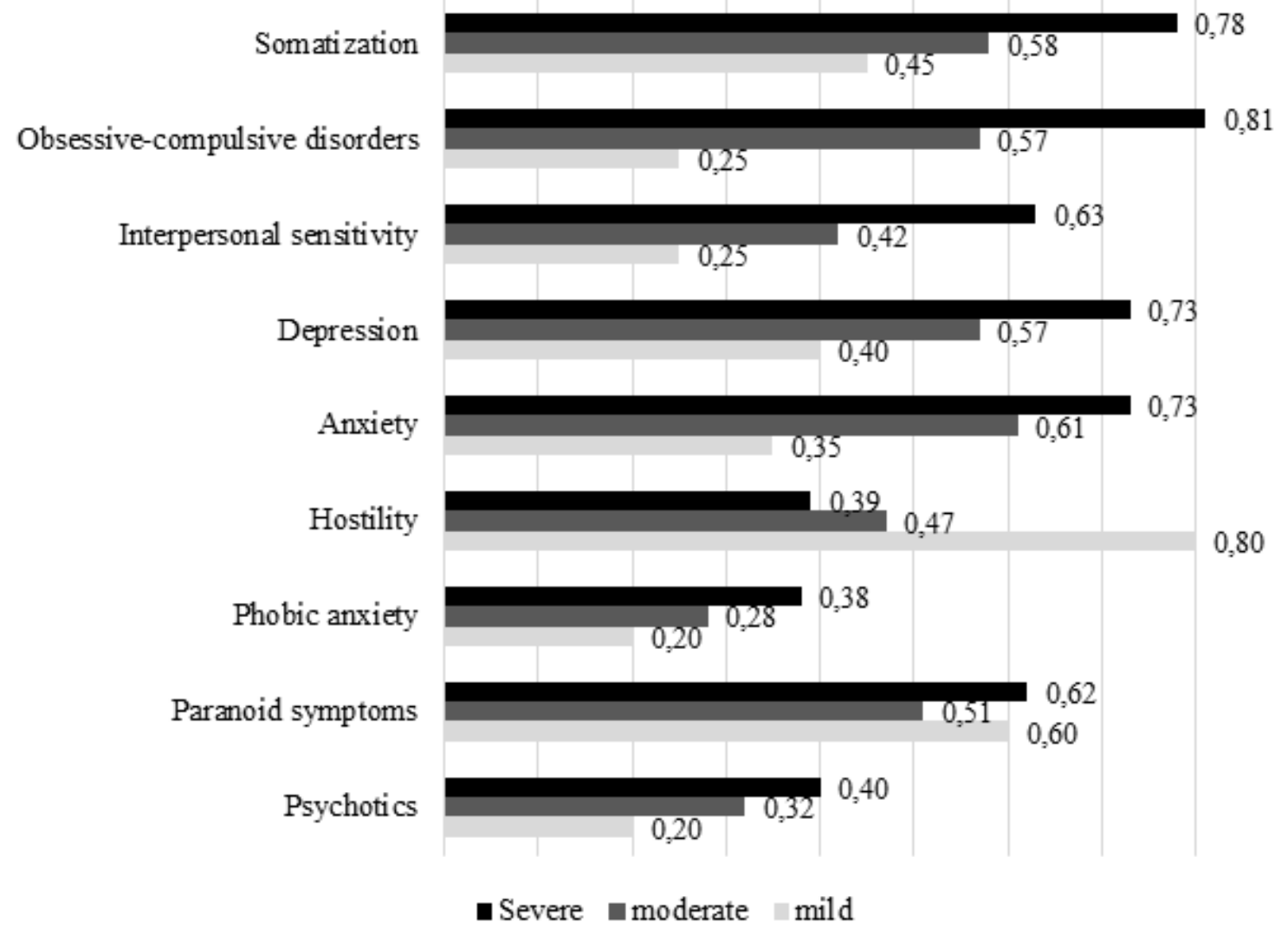

Fig. 2. Indices of the severity of psychopathological symptoms among combatants with alcohol dependence and different degrees of psychosocial stress

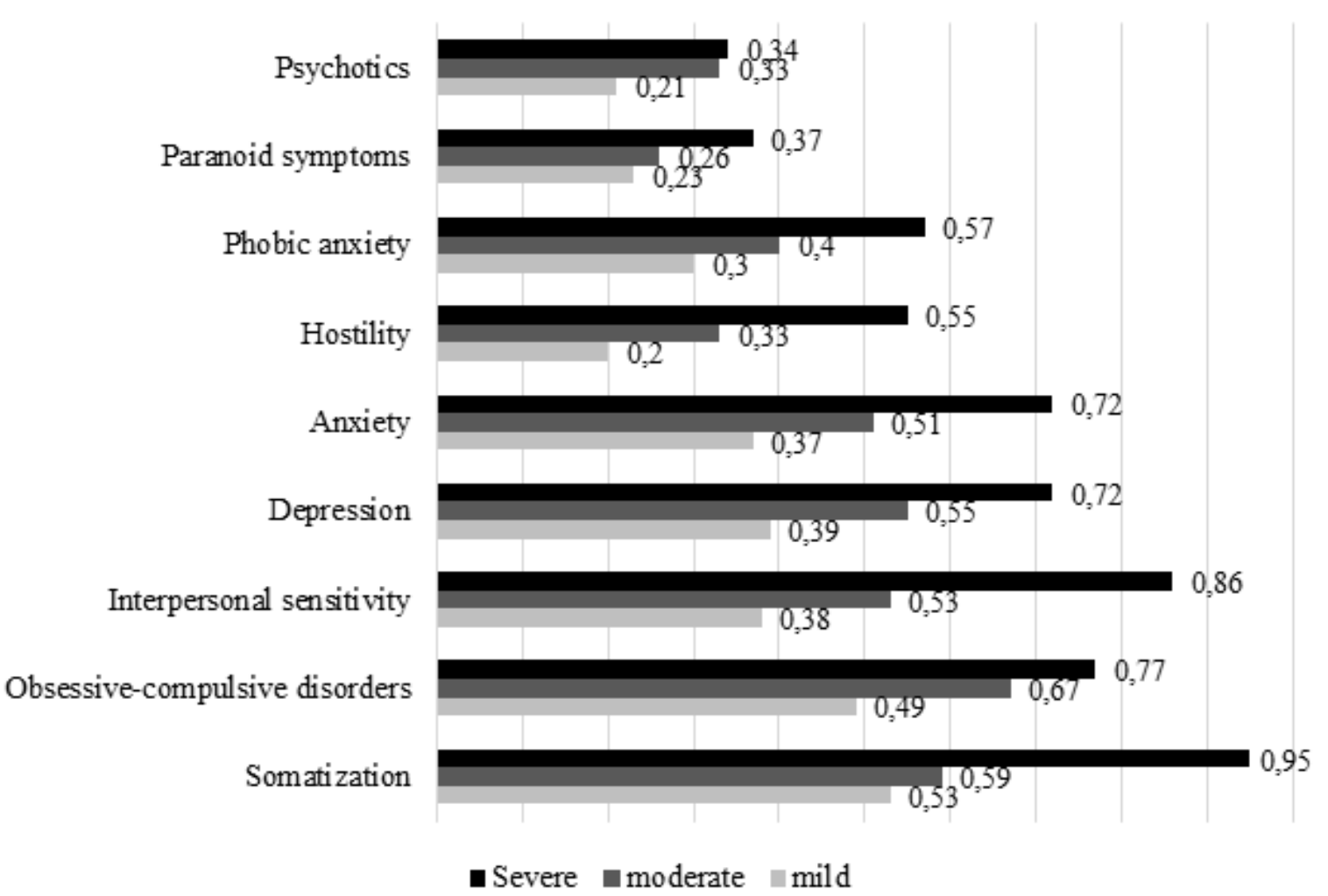

Fig. 3. Indices of the severity of psychopathological symptoms among forcibly displaced persons with alcohol dependence and different degrees of psychosocial stress 
characterized by the lowest quantitative indices, with the highest degree of psychosocial stress the highest rates, and indices in the group with a moderate degree of psychosocial stress occupied an intermediate position. Most clearly these differences were expressed for depression, somewhat less for interpersonal sensitivity, paranoid symptomatology and psychoticism. The General Symptomatic Index (GSI) among displaced persons was significantly increasing $(p<0.05)$ with an increase in the severity of psychosocial stress: in the DP1 group it was 0.40 \pm 0.12 points, in the DP2 group it was $0.57 \pm 0.12$ points, in the DP3 group $-0,76 \pm 0,28$ points. The Positive Symptomatic Index (PSI) significantly differed in the groups DP1 (23.22 \pm 5.70 points) and DP2 (28.77 \pm 4.47 points), and not significantly differed in the groups $\mathrm{P} 2$ and $\mathrm{P} 3$ $(31.26 \pm 8.40$ points $)$. Significant $(p<0.05)$ discrepancies between the groups were found for the PDSI index, while the severity of the distress was increasing with the increase in the severity of psychosocial stress: in the DP1 group it was $1.59 \pm 0.15$ points, in the DP2 group $-1.78 \pm 0.20$ points, in the DP3 group $-2.14 \pm 0.25$ points.
The highest degree of the regularities regarding the increase in the severity of psychopathological symptoms combined with the increase in the severity of psychosocial stress were expressed in the group of local residents (groups L1, L2, L3 in fig. 4): virtually all psychopathological symptoms revealed statistically significant differences in the indices between the groups with mild, moderate and severe psychosocial stress. The integral indices in this group showed a clear tendency to increase with the increase in the severity of psychosocial stress. Thus, the General Symptomatic Index (GSI) in the L1 group was $0.30 \pm 0.08$ points, in the L2 group - $0.50 \pm 0.16$ points, in the L 3 group $-0.67 \pm 0.21$ points. The Positive Symptomatic Index (PSI) was $16.92 \pm 3.28$ points, $22.52 \pm 5.36$ points, and $27.19 \pm 6.69$ points, respectively. The PDSI index was $1.60 \pm 0.16$ points, $1.97 \pm 0.23$ points and $2.17 \pm 0.24$ points, respectively.

In our opinion, this may be due to significantly higher severity of psychosocial stress in groups of combatants and displaced persons, and the more complex nature of the response to stress in these groups, which has

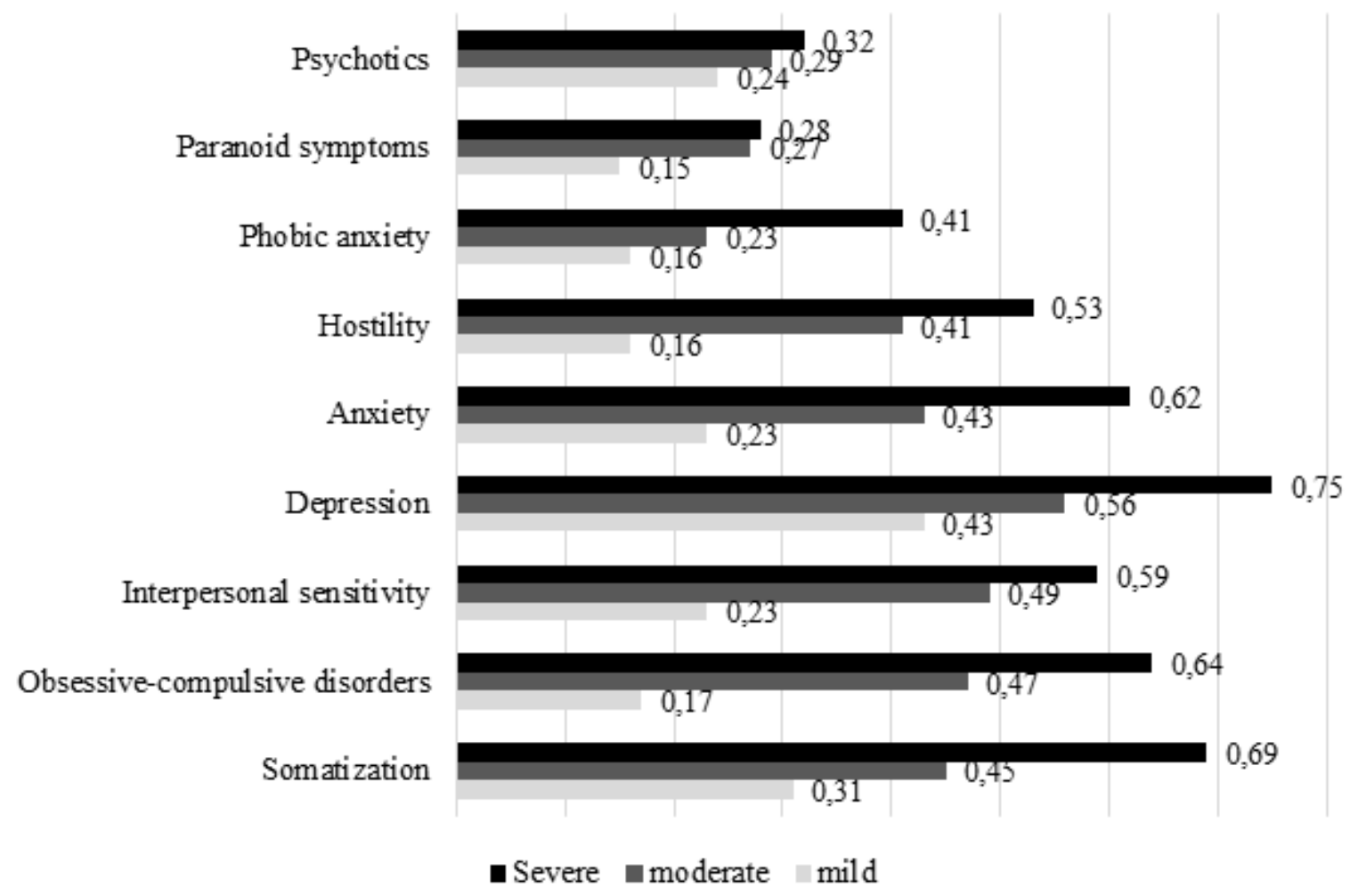

Fig. 4. Indices of the severity of psychopathological symptoms among local residents with alcohol dependence and different degrees of psychosocial stress 
led to more complicated patterns, especially in the group of combatants.

\section{Conclusions}

Thus, the study has shown that the clinical diversity and severity of alcohol-related disorders and their psychopathological arrangement are associated with the severity of psychosocial stress experienced by patients.
The factor of availability of psychotraumatic experience itself not associated with a distinct response to a stressful event does not significantly affect the variability of the psychopathological symptoms of persons with alcohol dependence, which significantly influences the choice of therapeutic strategies for the individual contingents of these patients.

\section{References}

1. Degenhardt L, Charlson F, Ferrari A, Santomauro D, Erskine H, Mantilla-Herrara A, ... Vos T. (2018). The global burden of disease attributable to alcohol and drug use in 195 countries and territories, 1990-2016: a systematic analysis for the Global Burden of Disease Study 2016. Lancet Psychiatry. Nov 1. pii: S2215-0366(18)30337-7. doi: 10.1016/S2215-0366(18)30337-7.

2. Maruta N.O., Kalens `ka G.Yu., Yavdak I.O., Malyuta L.V. (2018) Rozlady` psy’xichnogo zdorov'ya u vnutrishn`o peremishheny`x osib (Disorders of Mental Health in Internally Displaced Persons). Ukrayins 'ky`j visny`k psy`xonevrologiyi. T. 26, vy`p. 2 (95). S. 68-71.

3. Deny`senko M.M., Laky`ns 'ky`j R.V., Shestopalova L.F., Lins`ky`j I.V. (2017) Osnovni klinichni varianty' poststresovy'x rozladiv u kombatantiv (The main clinical variants of post-stress disorder in combatants) Ukrayins`ky`j visny`k psy`xonevrologiyi. T. 25, vy`p. 2 (91). S. 40-44.

4. Markova M. V., Gaponov K. D. (2016). Post-stressed disorders in servicemen who took part in the fighting: prevalence and expected consequences. WPA Congress of Epidemiology and Public Health 2016, 29.03 - 01.04.2016. Book of Abstracts. - Munich, Institute of Psychiatric Phenomics and Genomics, 2016. P. 30-31.

5. Gaponov K.D. (2016) Alkogol'na zalezhnist' v umovax social 'nogo stresu: epidemiologichni, klinichni i likuval'ni aspekty' (Alcohol dependence in conditions of social stress: epidemiological, clinical and medical aspects). Ukrayins 'ky`j visny`k psy`xonevrologiyi. Tom 24, vy’p. 4 (89). S. 54-60.

6. Gaponov K.D. (2018). Alkogol'na zalezhnist' i social 'ny’j stres: bioximichni, nejrofiziologichni i psy`xosocial'ni mexanizmy` vzayemovply`vu (Alcohol dependence and social stress: biochemical, neurophysiological and psychosocial mechanisms of mutual influence). Ukrayins 'ky’j visny`k psy’xonevrologiyi. T. 26, vy`p. 1 (94). S. 104-109.

7. Babor Th. F., Higgins-Biddle J. C., Saunders J. B., Monteiro M. G. (2001). AUDIT. Alcohol Use Disorders Identification Test. WHO/MSD/MSB/01.6a Original: English Distribution: General. 28 p.

8. Stockwell T., Sithavan T., McGrath D. (1994). The measurement of alcohol dependence and impaired control in community samples. Addiction.. Vol. 89. P. 167-174.

9. Gaponov K.D., Sosin I.K., Goncharova O.Yu., Markova M.V. (2018). Sposib diagnosty'ky' klinichnoyi specy`fiky' i prognozu perebigu alkogol'noyi zalezhnosti u osib z rizny'm psy'xotravmaty 'chny'm dosvidom i rivnem psy'xosocial 'nogo stresu (A method of diagnostics of clinical specificity and prognosis of the course of alcohol dependence in people with different psychotraumatic experiences and levels of psychosocial stress). Informacijny ’j ly`st MOZ Ukrayiny`\# 249-2018. $4 \mathrm{~s}$.

10. Vodop 'yanova N.E. (2009). Psy`xody`agnosty`ka stressa (Psychodiagnosis of stress). SPb.: Py`ter. $336 \mathrm{~s}$.

11. Tarabry`na N.V. (2001). Prakty kum po psy`xology`y` posttravmaty`cheskogo stressa (Practicum on the psychology of post-traumatic stress). SPb: Py'ter. 272 s.

Received: 18-Jan-2019

Accepted: 18-Mar-2019 